\title{
AWARENESS REGARDING DIABETES AND ITS MANAGEMENT AMONGST PATIENTS VISITING TERTIARY CARE HOSPITALS AND ITS IMPACT ON GLYCEMIC CONTROL
}

\author{
Anum Khan, Asif Farooq, Abdul Rehman Arshad, Sheharyar Raashid \\ Pak Emirates Military Hospital/National University of Medical Sciences (NUMS) Rawalpindi Pakistan
}

ABSTRACT

\begin{abstract}
Objective: To assess factors affecting disease awareness in diabetics, and its association with glycemic control.
Study Design: Cross-sectional analytical study.

Place and Duration of Study: Department of Medicine, Pak Emirates Military Hospital Rawalpindi from Jan to Apr 2019.

Methodology: Outdoor patients with type-II diabetes mellitus were selected using a consecutive sampling technique. Disease awareness was assessed with a modified Diabetes Knowledge Questionnaire, with scores $>70 \%$ considered satisfactory. Recent HbA1c levels were used to determine glycemic control ( $<7 \%$ reflecting good glycemic control). Demographic data, including age, gender, level of education, residence, duration of diabetes, mode of treatment, smoking status and co-existing hypertension, were also recorded.

Results: There were 212 patients with equal gender distribution and mean age of $55.90 \pm 11.96$ years. Of these, 117 (55.18\%) lived in rural areas, 77 (36.32\%) were educated, 34 (16.03\%) were smokers and 121 (57.07\%) had co-existing hypertension. The mean duration of diabetes was $81.72 \pm 71.67$ months (range 3-360 months) and mean HbA1c levels were $9.55 \pm 2.56 \%$. Higher $\mathrm{HbA1c}$ levels were associated with poorer DKQ scores. The level of education and the duration of diabetes significantly predicted DKQ scores.

Conclusion: Lack of disease awareness leads to poor glycemic control. Better education and longer disease duration impact the understanding of diabetes.
\end{abstract}

Keywords: Awareness, Glycemic control, Type-II diabetes mellitus.

How to Cite This Article: Khan A, Farooq A, Arshad AR, Raashid S. Awareness Regarding Diabetes and Its Management Amongst Patients Visiting Tertiary Care Hospital and Its Impact on Glycemic Control. Pak Armed Forces Med J 2021; 71(5): 1815-1819. ～doi: https://doi.org/10.51253/pafmj.v71i5.2998

This is an Open Access article distributed under the terms of the Creative Commons Attribution License (https://creativecommons.org/licenses/by-nc/4.0/), which permits unrestricted use, distribution, and reproduction in any medium provided the original work is properly cited.

\section{INTRODUCTION}

Diabetes mellitus is the most prevalent non-communicable disease and has emerged as the pandemic of the $21^{\text {st }}$ century. About 425 million people have diabetes worldwide, with numbers expected to rise to 600 million by 2045. ${ }^{1}$ International Diabetes Federation reported $7.6-11 \%$ prevalence of diabetes in the Pakistani population in 2011 , projected to rise to $15 \%$ by $2030 . .^{2}$ Diabetes has become a huge burden on the health care resources of the developing world due to its chronic nature and associated morbidities. ${ }^{3}$

Management of diabetes is a challenge for physicians. Treatment aims at achieving glycemic control with lifestyle changes and a wide array of pharmacological agents. These need to be continued for life as there is no curative treatment. Educating and motivating the patients to adopt a healthy lifestyle and remain adherent to drug treatment can help achieve good glycemic control and prevent the development of complications. ${ }^{4,5}$ Thus, education regarding self-mana-

Correspondence: Dr Anum Khan, Resident Medicine, Pak Emirates Military Hospital, Rawalpindi Pakistan

Received: 23 Jun 2020; revision received: 23 Feb 2020; accepted: 25 Feb 2020 gement and sustained control is a cornerstone of the disease's management; the ultimate target is a change in attitude. ${ }^{6,7}$

Though there is abundant literature from the developed world on this topic, local data is scarce. Our patients come from different cultural backgrounds and the results of international studies may apply to our setups. This study was therefore planned to study the correlation between diabetes knowledge and glycemic control and to determine demographic factors that could predict a better understanding of the disease process. This would in turn allow us to focus more on patients less likely to have a clear understanding of diabetes and its management.

\section{METHODOLOGY}

This cross-sectional analytical study was carried out at the Department of Medicine, Pak-Emirates Military Hospital Rawalpindi, from January to April 2019, after seeking approval from the Ethics Review Board of the Institute (Ltr no A/28 dated 30 th November 2018). We enrolled outdoor patients using consecutive sampling techniques, after taking informed oral consent. 


\section{Inclusion Criteria}

Patients with Type 2 Diabetes Mellitus who were able to understand and communicate in Urdu were included.

\section{Exclusion Criteria}

Patients who did not give consent, those having Type 1 diabetes and the ones who had some cognitive deficit or who could not communicate effectively for answering the questions were excluded.

We calculated a minimal sample size of 108 , using Free Statistics Calculator version 4 . We assumed 8 predictions in the model, anticipated effect size (f2) of 0.158 , alpha of 0.05 , and beta 0.8 . Since the latter size requirement was larger, we decided to enrol at least 108 patients for this study.

Socio-demographic and disease-related variables, such as age, gender, education, area of residence, smoking status, hypertension, duration and treatment of diabetes were recorded. The latest $\mathrm{HbA1c}$ done at any time during the last 3 months was used for assessment of glycemic control; HbA1c $<7 \%$ was labelled as optimum level. Those having passed matriculation and above were considered to have good education as compared to the rest with poor education. Awareness about diabetes was assessed with a slightly modified Urdu version of the Diabetes Knowledge Questionnaire (DKQ). This is self-explanatory and patients were asked to fill up the answers on their own. Each correct answer carried one mark, with no negative marking. A total score out of a maximum of 23 was calculated for each patient. Those with a total DKQ score of 17 or more $(>70 \%)$ were acknowledged to have good diabetes awareness.

Statistical Package for the social sciences (SPSS) version 23 was used to analyse the data. Quantitative variables were described as mean \pm standard deviation. Linear regression analysis was done to find the association between DKQ scores with HbA1c. Binary logistic regression was done to determine the relationship of various different demographic parameters with DKQ scores. The $p$-value of $\leq 0.05$ was considered significant.

\section{RESULTS}

A total of 212 patients with equal gender distribution were included. Mean HbA1c was $9.55 \pm 2.56 \%$,

Table-I: Baseline characteristics and factors associated with poor diabetes knowledge.

\begin{tabular}{|c|c|c|c|c|c|c|c|c|}
\hline \multirow[b]{2}{*}{ Factors } & \multicolumn{2}{|c|}{ Diabetes awareness } & \multicolumn{3}{|c|}{ Univariate logistic regression } & \multicolumn{3}{|c|}{ Multivariate logistic regression } \\
\hline & Good & Poor & $\begin{array}{c}p- \\
\text { value }\end{array}$ & $\begin{array}{l}\text { Un-adjusted } \\
\text { OR }\end{array}$ & $\begin{array}{c}95 \% \text { CI for } \\
\text { UOR }\end{array}$ & $p$-value & $\begin{array}{l}\text { Adjusted } \\
\text { OR }\end{array}$ & $\begin{array}{c}95 \% \text { CI for } \\
\text { AOR }\end{array}$ \\
\hline $\begin{array}{l}\text { Age } \\
(\text { Mean } \pm \text { SD) }\end{array}$ & $\begin{array}{c}56.12 \pm \\
12.24\end{array}$ & $\begin{array}{c}55.76 \pm \\
11.82\end{array}$ & 0.832 & 1.002 & $0.980-1.026$ & & & \\
\hline $\begin{array}{l}\text { Duration of Diabetes } \\
\text { (months) }\end{array}$ & $\begin{array}{c}94.84 \pm \\
76.56\end{array}$ & $\begin{array}{c}72.77 \pm \\
66.99\end{array}$ & 0.030 & 1.004 & $1.000-1.008$ & 0.048 & 1.004 & $1.000-1.008$ \\
\hline \multicolumn{9}{|l|}{ Gender } \\
\hline Male & $48(55.8)$ & $58(46.0)$ & 1 & & & & & \\
\hline Female & $38(44.2)$ & $68(54.0)$ & 0.163 & 1.481 & $0.853-2.570$ & & & \\
\hline \multicolumn{9}{|l|}{ Residence } \\
\hline Rural & $45(52.3)$ & $72(57.1)$ & 1 & & & & & \\
\hline Urban & $41(47.7)$ & $54(42.9)$ & 0.489 & 0.823 & $0.474-1.428$ & & & \\
\hline \multicolumn{9}{|l|}{ Education Level } \\
\hline $\begin{array}{l}\text { Matriculation and } \\
\text { above }\end{array}$ & $41(47.7)$ & $36(28.6)$ & 1 & & & 1 & & \\
\hline $\begin{array}{l}\text { Middle school and } \\
\text { below }\end{array}$ & $45(52.3)$ & $90(71.4)$ & 0.005 & 0.439 & $0.248-0.779$ & 0.008 & 0.454 & $0.254-0.810$ \\
\hline \multicolumn{9}{|l|}{ Treatment } \\
\hline No treatment & 2 & 9 & 1 & & & & & \\
\hline Oral hypoglycemics & 56 & 99 & 0.574 & 0.566 & $0.078-4.126$ & & & \\
\hline Insulin & 17 & 19 & 0.916 & 0.895 & $0.113-7.064$ & & & \\
\hline $\begin{array}{l}\text { Insulin and oral } \\
\text { hypoglycemics }\end{array}$ & 11 & 6 & 0.589 & 1.833 & $0.204-16.512$ & & & \\
\hline \multicolumn{9}{|l|}{ Smoking } \\
\hline Yes & $11(12.8)$ & $23(18.3)$ & 1 & & & & & \\
\hline No & $75(87.2)$ & $103(81.7)$ & 0.289 & 0.657 & $0.302-1.429$ & & & \\
\hline \multicolumn{9}{|l|}{ Hypertension } \\
\hline Yes & $46(53.5)$ & 75 (59.5) & 1 & & & & & \\
\hline No & $40(46.5)$ & $51(40.5)$ & 0.384 & 0.782 & $0.450-1.360$ & & & \\
\hline
\end{tabular}


with $177(83.49 \%)$ patients having poor glycemic control. Linear regression analysis revealed that awareness about diabetes could predict $\mathrm{HbA1c}$ levels significantly $(\mathrm{F}=9.43, \mathrm{R} 2=0.043, p=0.02)$ and that the total DKQ score accounted for $3.8 \%$ of the explained variability in $\mathrm{HbA1c}$ levels. The scatter plot in the Figure depicts this. Amongst the socio-demographic and disease-related variables, duration of diabetes (adjusted odds ratio: 1.004; 95\% CI 1.00, 1.08; $p=0.048$ ) and education level (adjusted odds ratio: 0.454; 95\% CI 0.254, 0.810; $p: 0.008$ ) were significantly associated with DKQ scores. These two variables remained significant on multivariate regression as well, with $p$-values of 0.048 and 0.008 respectively (Table-I). Mean DKQ scores of $15.55 \pm 3.41$ were observed, with $86(40.56 \%)$ patients having good knowledge of diabetes.

Proportions of patients correctly answering individual questions on the DKQ are shown in Table II. Most of the patients were aware of diabetic complications including nephropathy, neuropathy and impaired wound healing. On the other hand, only a very small proportion knew that patients with diabetes could use iodine or alcohol to cleanse their wounds. ling economy. This can be reduced by controlling the disease by providing better awareness regarding disease management, adherence to treatment and compli-

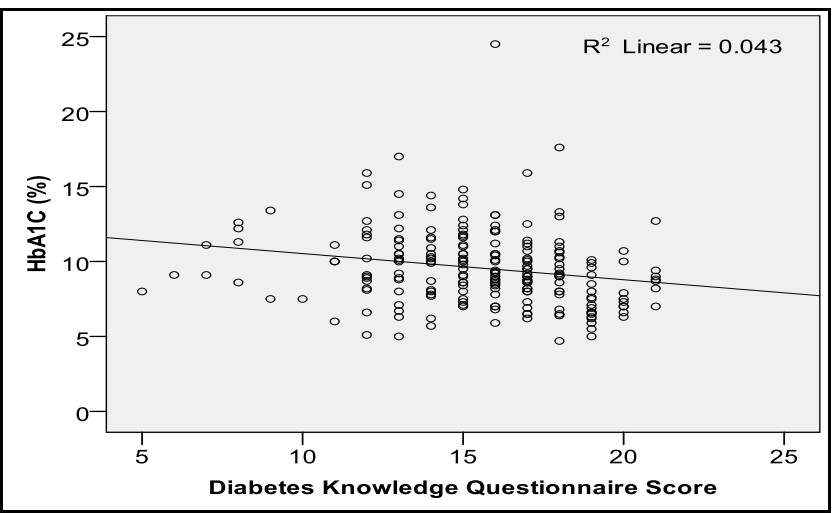

Figure: Correlation between diabetes knowledge score and glycemic control.

cations to the patients with diabetes.

We used $\mathrm{HbA1c}$ as the indicator of glycemic control as it is one of the standard criteria for diabetes diagnosis. ${ }^{9}$ It is the best test for determining long-term blood glucose levels, as it indicates the average blood sugar over the previous 2-3 months. ${ }^{10}$ Our study sho-

Table-II: Responses to individual questions of Diabetes Knowledge Questionnaire.

\begin{tabular}{l|c}
\hline Question & Correctly Answered n (\%) \\
\hline Eating too much sugar and other sweet foods is a cause of diabetes. & $32(15.09)$ \\
\hline The usual cause of diabetes is lack of effective insulin in the body. & $164(77.35)$ \\
\hline Diabetes is caused by the failure of the kidneys to keep sugar out of the urine. & $56(26.41)$ \\
\hline Kidneys produce insulin. & $208(50.94)$ \\
\hline In untreated diabetes, the amount of sugar in the blood usually increases. & $171(80.66)$ \\
\hline If I am diabetic, my children have a higher chance of being diabetic. & $149(70.28)$ \\
\hline Diabetes can be cured. & $190(89.62)$ \\
\hline A fasting sugar level of 210 is too high. & $138(65.09)$ \\
\hline The best way to check my diabetes is by testing my urine. & $168(79.24)$ \\
\hline Regular exercise will increase the need for insulin or diabetic medication. & $76(35.84)$ \\
\hline There are two main types of diabetes: Type 1 and Type 2 & $156(73.58)$ \\
\hline Medication is more important than diet and exercise to control diabetes. & $166(78.30)$ \\
\hline Diabetes often causes poor circulation. & $197(92.92)$ \\
\hline Cuts and abrasions on diabetes heal more slowly. & $198(93.39)$ \\
\hline Diabetics should take extra care when cutting their toenails. & $18(8.49)$ \\
\hline A person with diabetes should cleanse a cut with iodine and alcohol. & $167(78.77)$ \\
\hline The way I prepare my food is as important as the foods I eat. & $194(91.50)$ \\
\hline Diabetes can damage my kidneys & $199(93.86)$ \\
\hline Diabetes can cause loss of feeling in my hands, fingers and feet. & $90(42.45)$ \\
\hline Shaking and sweating are signs of high blood sugar. & $150(70.75)$ \\
\hline Frequent urination and thirst are signs of low blood sugar & $124(58.49)$ \\
\hline Tight elastic hose or stockings are not bad for diabetics. & $107(50.47)$ \\
\hline A diabetic diet consists mostly of special foods. & \\
\hline
\end{tabular}

\section{DISCUSSION}

Pakistan is one of the countries with the fastest rates of increasing diabetic patients in Southeast Asia. ${ }^{2}$ Diabetes is posing an enormous burden on our strugg- wed poor knowledge of diabetes amongst most diabetes patients and poor glycemic control. Better education and a longer duration of diabetes had a significant positive association with diabetes knowledge. There 
was a strong association of poor knowledge with poor diabetes control. The role of diabetes awareness in improving glycemic control has also been validated by other researches. ${ }^{11-13}$

Iqbal et al reported inadequate awareness about diabetes in the majority of diabetes from Islamabad. ${ }^{14}$ They put this down to lower educational levels in their cohort of patients. Similarly, in a study done at Peshawar, Fahim Ullah and his colleagues documented a poor understanding of diabetes-related complications in $37.50 \%$ of patients. ${ }^{15}$ Nearly four out of every five $(79 \%)$ patients in this study population were illiterate. Comparable results have been documented in other national studies as well. ${ }^{16}$ Knowledge, attitude and practices of type 2 diabetics in our population are unsatisfactory, emphasizing the need for stronger educational empowerment of our patients. Education levels have been implicated to have a positive impact on the disease awareness and control of diabetes in our patients; similar results were indicated by Kiberenge, et al. ${ }^{17}$

Greater duration of disease has shown to increase the disease awareness amongst our patients. These patients get well conversed with various aspects of their illness over time once they develop the complications of long-standing diabetes.

Awareness about diabetes is usually assessed by the well-recognized Diabetes Knowledge Questionnaire (DKQ) which has been successfully employed in other similar studies. ${ }^{18}$ We used the Urdu version of this questionnaire, the psychometric properties of which have been validated by Bukhsh, et al. 10 The questionnaire consists of 24 items. We excluded ques-tion no 12 in this study because the Urdu statement mentioned by Bukhsh, et al, is very difficult to comprehend and any simpler transliteration would make guessing very easy.

An advantage of administering the diabetes questionnaire was that the patients were told about the correct answers afterwards, which added to their knowledge. The patients lacked information regarding insulin production ( $49 \%$ answered correctly), diabetes cannot be cured ( $30 \%$ answered correctly), the ideal test for diabetes ( $35 \%$ answered correctly), the role of exercise (21\% answered correctly), cleaning of wounds ( $8 \%$ answered correctly), signs of high and low blood sugars (57\% and $29 \%$ answered correctly), the adverse role of tight stockings in diabetes $(41 \%$ answered correctly) and diet in diabetes ( $49 \%$ answered correctly).
Our patients had good knowledge about target blood sugar levels, as many of them had glucometers at home for blood glucose monitoring and otherwise they underwent the tests for blood sugars routinely from the laboratory during each outpatient visit. They had good awareness about the various complications of diabetes, such as delayed wound healing, neuropathy, nephropathy and vasculopathy. This could be explained by the possibility that many patients had already developed these complications. Furthermore, their interaction with other diabetic patients in the hospital and the community-made them aware of each other's experiences and problems with the disease.

This research highlights the concern that although our patients were well conversant with diabetes complications, they have poor knowledge of how to control the disease and prevent these complications and the importance of diet and exercise. Similar results were reported in a Nigerian study. ${ }^{19}$ Moreover, they were unaware of the signs of hypoglycaemia and hyperglycaemia, which can predispose them to fatal events.

Hence, educating diabetic patients and imparting them relevant information regarding their disease can change their attitude and practices in self-care and management, which can improve long term glycaemic control and prevent complications. ${ }^{20-23}$ Developing evidence-based free-of-cost education programmes for diabetics and making them available to the patients with lack of access to health care facilities (who make up the major portion of our population) can be very beneficial.

\section{LIMITATION OF STUDY}

The limitations of this study were that we included only patients with type 2 diabetes mellitus, thus the awareness and glycemic was not assessed in type 1 diabetics. Patients were not followed up after the one-time encounter in the outpatient department. Thus, the impact on subsequent $\mathrm{HbA1c}$ and knowledge levels could not be assessed. This study was carried out at a single centre; a multicentre study would have provided stronger results. Only patients able to understand the Urdu language were included. They are usually the ones with better literacy, which can lead to bias in results, as they cannot represent the whole population. The levels of diabetes awareness have possibly been overestimated, as the patients visiting our set-up have access to better health care facilities due to their entitlement for 3 free medical check-ups (the tip of the iceberg). They are bound to have a better awareness of their illness as compared to their contemporaries with poor facilities and having a lack of access to health care facilities. 


\section{CONCLUSION}

Knowledge about the disease improves glycemic control in our patients. Awareness about diabetes needs to be promoted in our population, which has generally a poor trend towards diabetes management and glycemic control.

\section{Conflict of Interest: None.}

\section{Authors' Contribution}

AK: Data collection, data analysis, proof reading, AF: interpretation of data, ARA: Data analysis, review, SR: data anaysis, proof reading.

\section{REFERENCES}

1. Toniolo A, Cassani G, Puggioni A, Rossi A, Colombo A, Onodera $\mathrm{T}$, et al. The diabetes pandemic and associated infections: suggestions for clinical microbiology. Rev Med Microbiol 2019; 30(1): $1-17$.

2. Hussain A, Ali I. Diabetes mellitus in Pakistan: A major public health concern. Arch Pharma Pract 2016; 7(1): 30-32.

3. Zhang $P$, Zhang $X$, Brown J, Vistisen D, Sicree R, Shaw J, et al. Global healthcare expenditure on diabetes for 2010 and 2030. Diabetes Res Clin Pract 2010; 87(3): 293-301.

4. Healy SJ, Dungan KM. Monitoring glycemia in diabetes. Med Clin North Am 2015; 99(1): 35-45.

5. American Diabetes Association. Classification and diagnosis of diabetes: standards of medical care in diabetes 2018. Diabetes Care 2018; 41(Suppl-1): S13-S27.

6. Burke SD, Sherr D, Lipman RD. Partnering with diabetes educators to improve patient outcomes. Diabetes Metab Syndr Obes 2014; 7(2): 45-53.

7. Essien O, Otu A, Umoh V, Enang O, Hicks JP, Walley J. Intensive patient education improves glycemic control in diabetes compared to conventional education: a randomised controlled trial in a Nigerian tertiary care hospital. PLoS One 2017; 12(1): e0168835.

8. Simple linear regression [Internet]. Hong Kong: The Chinese University of Hong Kong; [Internet] Available from: https:// www2.ccrb.cuhk.edu.hk/stat/epistudies/reg1.htm [Accessed Jan 31, 2020].

9. American Diabetes Association. Executive summary: Standards of medical care in diabetes-2010. Diabetes Care 2010; 33(Suppl-1): S4-10.

10. Bukhsh A, Lee SWH, Pusparajah P, Khan AH, Khan TM. Psychometric properties of the Urdu version of diabetes knowledge questionnaire. Front Public Health 2017; 5(1): 139-145.
11. Ozcelik F, Yiginer O, Arslan E, Serdar MA, Uz O, Kardesoglu E, et al. Association between glycemic control and the level of knowledge and disease awareness in type 2 diabetic patients. Pol Arch Med Wewn 2010; 120(10): 399-406.

12. Kassahun T, Eshetie T. Factors associated with gly-cemic control among adult patients with type 2 diabetes mellitus: a crosssectional survey in Ethiopia. BMC Res Notes 2016; 9(2): 78-82.

13. Yang H, Gao J, Ren L, Li S, Chen Z, Huang J, et al. Association between knowledge-attitude-practices and control of blood glucose, blood pressure, and blood lipids in patients with type 2 diabetes in Shanghai, China: a cross-sectional study. J Diabetes Res 2017; 2017(2): 3901392.

14. Iqbal T, Rashid F, Saleem SA, Shah SA, Khalid GH, Ishtiaq O. Awareness about diabetes mellitus amongst diabetics. J Rawalpindi Med Coll 2013; 17(2): 294-296.

15. Ullah F, Afridi AK, Rahim F, Ashfaq M, Khan S, Shabbier G, et al. Knowledge of diabetic complications in patients with diabetes mellitus. J Ayub Med Coll Abbottabad 2015; 27(2): 360-363.

16. Gul N. Knowledge, attitudes and practices of type 2 diabetic patients. J Ayub Med Coll Abbottabad 2010; 22(3): 128-131.

17. Kiberenge MW, Ndegwa ZM, Njenga EW, Muchemi EW. Knowledge, attitude and practices related to diabetes among community members in four provinces in Kenya: a cross-sectional study. Pan Afr Med J 2010; 7(2): 2-8.

18. Shams N, Amjad S, Seetlani NK, Ahmed W. Diabetes knowledge in elderly type 2 diabetes mellitus patients and association with glycemic control. J Liaquat Uni Med Health Sci 2016; 15(2): 71-77.

19. Okolie, Uchenna V, Ehiemere, Ijeoma O, Iheanacho, Peace N. Knowledge of diabetes management and control by diabetic patients at Federal Medical Center Umuahia Abia State, Nigeria. Int J Med Med Sci 2009; 1(9): 353-358.

20. Musenge EM, Michelo C, Mudenda B, Manankov A. Glycaemic control and associated self-management behaviours in diabetic outpatients: a hospital-based observation study in Lusaka, Zambia. J Diabetes Res 2016; 2016(2): 7934654.

21. Foma MA, Saidu Y, Omoleke SA,Jafali J. Awareness of diabetes mellitus among diabetic patients in The Gambia: a strong case for health education and promotion. BMC Public Health 2013; 13(1): 1124 .

22. Chrvala CA, Sherr D, Lipman RD. Diabetes self-management education for adults with type 2 diabetes mellitus: A systematic review of the effect on glycemic control. Patient Educ Couns 2016; 99(6): 926-943.

23. Al-Maskari F, El-Sadig M, Al-Kaabi JM, Afandi B, Nagelkerke N, Yeatts KB. Knowledge, attitude and practices of diabetes patients in the United Arab Emirates. Plos One 2013; 8(2): e52857. 